\title{
РАСТИТЕЛЬНАЯ КЛЕТОЧНАЯ СТЕНКА В СИМБИОТИЧЕСКИХ ВЗАИМОДЕЙСТВИЯХ. ПЕКТИНЫ
}

\author{
(обзор)
}

\author{
А.В. ЦЫГАНОВА, В.Е. ЦЫГАНОВ
}

Поскольку растительные клетки, в отличие от животных, неподвижны и ограничены жесткими клеточными стенками, часто свойства растительного внеклеточного матрикса играют решающую роль в развитии растения. Внеклеточный матрикс, в частности клеточные стенки, вовлечены в молекулярный диалог между партнерами во время взаимодействия растений и микроорганизмов при формировании бобово-ризобиального симбиоза (N.J. Brewin, 2004; M.K. Rich с соавт., 2014). Бобово-ризобиальный симбиоз служит удобной моделью для изучения изменений в составе растительной клеточной стенки, вызванных взаимодействием с бактериями. Колонизация клеток хозяина клубеньковыми бактериями - ризобиями включает последовательную перестройку растительно-микробного интерфейса. К бактериальным компонентам симбиотического интерфейса относятся различные поверхностные полисахариды (А.В. Цыганова с соавт., 2012), к растительным - клеточная стенка, межклеточный матрикс и плазматическая мембрана. В представляемом обзоре мы обобщили данные, демонстрирующие участие в бобово-ризобиальном симбиозе пектинов - полисахаридов матрикса клеточных стенок (К.Н. Caffall с coавт., 2009; M.A. Atmodjo с coaвт., 2013; С.T. Anderson, 2015). Наиболыший прогресс достигнут в изучении гомогалактуронана, для которого получены высокоспецифичные моноклональные антитела (J.P. Кnох с соавт., 1990; Y. Verhertbruggen с соавт., 2009). Функция гомогалактуронана в клубеньках определяется степенью его метилирования. При низкой он участвует в повышении ригидности клеточных стенок и стенок инфекционных нитей (K.A. VandenBosch с соавт., 1989; A.L. Rae с соавт., 1992), что особенно проявляется при неэффективном взаимодействии с ризобиями (K.A. Ivanova с соавт., 2015) и влиянии абиотических факторов (М. Redondo-Nieto с соавт., 2003, 2007; M. Sujkowska-Rybkowska с соавт., 2015). Высокометилэтерефицированный гомогалактуронан присутствует в клеточных стенках на всех стадиях развития клубенька (A.L. Rae с соавт., 1992; A.V. Tsyganova c соавт., 2019). Отсутствие охарактеризованных антител осложняет изучение рамногалактуронана-II (M.A. O’Neill с соавт., 2004). Тем не менее было показано, что в клубеньках рамногалактуронан-II присутствует в клеточных стенках на границе с плазматической мембраной, в недифференцированных симбиосомах, а также в матриксе инфекционных нитей (M. Redondo-Nieto с соавт., 2003, 2007; M. Reguera с соавт., 2010). Вероятно, рамногалактуронан-II в комплексе с бором и арабиногалактанпротеин-экстензинами способствует продвижению ризобий в матриксе инфекционных нитей (М. Reguera с соавт., 2010). Лишь недавно нами были проведены первые исследования по выявлению роли рамногалактуронана-I в развитии клубеньков (A.V. Tsyganova c coaвт., 2019) и показано, что рамногалактуронан-I присутствует в клеточной стенке клеток меристемы, проводящих пучков и стенках инфекционных нитей. Однако точная его функция остается невыясненной, хотя высказано предположение, что рамногалактуронан-I участвует в восприятии ризобий в качестве патогенов при неэффективном симбиозе (A.V. Tsyganova c соавт., 2019). Таким образом, к настоящему моменту известно, что в развитие симбиотического клубенька вовлечены все типы пектинов. При этом именно растение играет центральную роль в перестройке клеточной стенки во время симбиотического взаимодействия и построения растительно-микробного интерфейса.

Ключевые слова: бобово-ризобиальный симбиоз, растительно-микробный интерфейс, клеточная стенка, инфекционная нить, гомогалактуронан, рамногалактуронаны.

Взаимодействие с микроорганизмами, как патогенными, так и симбиотическими, присуще любому растению, произрастающему в естественных условиях. Каждая растительная клетка окружена сетью микрофибрилл целлюлозы - клеточной стенкой, которая практически полностью непроницаема для микроорганизмов (1-3). Как внешняя граница тела растения, клеточная стенка опосредует многие взаимодействия с окружающей средой, в том числе и взаимодействия с биотическими факторами (4-6). В процессе эволюции микроорганизмы развили две стратегии для преодоления барьера, создаваемого клеточной стенкой, и проникновения вглубь

\footnotetext{
* Работа финансово поддержана РНФ (грант № 16-16-10035). 
клетки. Первая заключается в растворении стенки растительной клетки, и она используется многими патогенными микроорганизмами. Вторая стратегия состоит в реорганизации клеточной стенки в точке проникновения микроорганизма. Эту стратегию используют и ризобии при проникновении вглубь корня. В результате локального ингибирования синтеза целлюлозы и модификации внеклеточного матрикса ризобия может, по сути, создавать субклеточную точку входа через целлюлозную сеть с минимальным повреждением клетки-хозяина и проявлением стрессовых и защитных реакций (7-9). При внутриклеточном росте инфекционной нити ее стенка строится подобно фрагмопласту $(7,9,10)$. При несовместимых взаимодействиях между ризобиями и бобовыми растениями внеклеточный матрикс модифицируется и становится более устойчив к инвазии за счет встраивания вторичных метаболитов, таких как суберин (11), или посредством сшивания белков клеточной стенки перекисью водорода (12).

Клеточные стенки и плазматические мембраны вовлечены в обмен веществ между партнерами во время взаимодействия растений и микроорганизмов, при этом симбиотические взаимодействия достигают полной функциональности благодаря развитию обширной контактной поверхности между хозяином и микросимбионтом - симбиотического интерфейса $(7,8)$. Клеточные стенки состоят в основном из полисахаридов, которые могут быть сгруппированы в три основных класса: целлюлоза, пектины и гемицеллюлозы $(1,3)$. В дополнение к полисахаридам большинство клеточных стенок растений содержат структурные белки, такие как экстензины и арабиногалактановые гликопротеины.

Впервые роль полисахаридов клеточных стенок в молекулярном обмене между партнерами во время взаимодействия растений и ризобий была показана в работах группы исследователей из John Innes Centre $(10,13,14)$.

Настоящий обзор посвящен обсуждению участия обширного класса полисахаридов клеточных стенок - пектинов в симбиотических взаимодействиях бобовых растений с ризобиями.

Пектин - важный элемент клеточной стенки двудольных растений, который, вероятно, представляет собой одну из самых сложных макромолекул в природе. Он состоит из 17 различных моносахаридов, на основе которых формируются различные полисахариды, образующие сеть (15). Пектины образуют семейство полисахаридов, богатых галактуроновой кислотой, включая гомогалактуронан (ГГ), рамногалактуронан-I (РГ-I) и замещенный галактуронан, рамногалактуронан-II (РГ-II), некоторые клеточные стенки растений также содержат дополнительные замещенные галактуронаны, известные как апигалактуронан и ксилогалактуронан (1618). Пектиновые полисахариды обладают многочисленными функциями в растениях: способствуют клеточной адгезии посредством, например, димеризации РГ-ІІ и сшивания ГГ; влияют на образование вторичных стенок в волокнах и древесине; создают резервуар олигосахаридных сигнальных молекул, важных для роста, развития и защитных реакций растений; обеспечивают ионный транспорт и водный режим в качестве гидратирующих полимеров, влияют на прорастание семян $(17,19,20)$. В результате многолетних исследований были получены моноклональные антитела, которые распознают различные пектиновые полимеры в клеточной стенке растений. Микроскопический анализ клеточных стенок, меченных антителами определенной специфичности, показал, что пектин в значительной степени способствует гетерогенности клеточных стенок растения в различных тканях и на разных этапах онтогенеза $(15,16,21-23)$.

Гомогалактуронаны клеточных стенок при формиро- 
вании симбиотических клубеньков. ГГ составляет примерно $65 \%$ пектина, он представляет собой линейную цепь (1-4)-связанных $\alpha$-D-галактуроновых кислот, при этом ГГ частично метилируется и в меньшей степени ацетилируется $(17,18)$. Во время клеточной дифференцировки ГГ синтезируется в аппарате Гольджи растения и секретируется в виде полимеров с высокой степенью метилирования $(16,24)$. Степень метилэтерификации и ацетилирования ГГ неодинакова у разных видов растений, она регулируется в процессе развития с помощью пектинметилэстераз, ингибиторов пектинметилэстераз, а также сериновыми протеазами субтилизинового типа и по меньшей мере одной Ез-убиквитинлигазой (25). Активность ферментов, которые деградируют пектин, напрямую зависит от присутствия метиловых эфиров $(26,27)$. Деэтерификация пектина с помощью пектинметилэстераз в клеточной стенке приводит к одному из двух противоположных сценариев $(28,29)$ : блоки деэтерифицированных остатков галактуроновой кислоты могут быть сшиты посредством ионов $\mathrm{Ca}^{2+}$ в форме «ящиков для яиц» («egg-box») для увеличения жесткости клеточной стенки $(5,16,25,30)$ либо расщеплены ферментами, деградирующими пектин (например, полигалактуроназами или пектатлиазами), для размягчения клеточной стенки (4, 31-33).

Пектинметилэстеразы участвуют в дифференцировке неинфицированных клеток в клубеньках, формирующихся на придаточных корнях тропического бобового растения Sesbania rostrata Bremek. and Oberm. при инокуляции Azorhizobium caulinodans (26). У Medicago truncatula Gaertn. из восьми дифференциально экспрессирующихся генов пектинметилэстераз ген MtPER относится к симбиотическим и функционирует на ранних стадиях взаимодействия с Sinorhizobium meliloti (34).

Электронно-микроскопические исследования показали, что ризобии проникают через небольшую деградированную область клеточной стенки растения. Известно участие ферментов, деградирующих клеточную стенку, в инфекционном процессе, что позволяет бактериям проникать внутрь растений $(4,33)$. У Rhizobium etli, вступающей в симбиоз с Phaseolus vulgaris L., был выявлен ген HrpW, относящийся к секреторной системе III типа, продукт которого проявлял ферментативную активность пектатлиазы (35). Одно из первых доказательств участия растительных ферментов, деградирующих клеточную стенку, в инфекционном процессе было получено при изучении гена полигалактуроназы M. sativa L. (MsPG3), специфически экспрессируемого во время симбиоза с $S$. meliloti (36). У Lotus japonicus (Regel) K. Larsen была выявлена пектатлиаза (LjNPL), которая индуцируется Nod-факторами и, по-видимому, участвует в проникновении ризобий в инфекционные нити (37).

Для детальной локализации ГГ в тканях растений часто используется иммунохимический метод, при этом частично или высокометилэтерифицированный ГГ распознается антителами JIM7 и LM20, тогда как низкометилэтерифицированный или деэтерифицированный - антителами JIM5 и LM19 $(38,39)$. Иммуноэлектронная микроскопия показала дифференциальное расположение эпитопов пектина в клеточных стенках (29). Деэтерифицированный ГГ, распознаваемый антителом JIM5, располагается на внутренней поверхности первичных клеточных стенок, прилегающих к плазматической мембране, в срединной пластинке и в большом количестве на внешней поверхности клеточных стенок, прилегающей к межклеточным пространствам. Напротив, высокометилэтерифицированный ГГ, распознаваемый антителом JIM7, распределен равномерно по всей клеточной стенке $(38,40)$. 
Локализация ГГ детально изучена у различных бобовых растений, инокулированных ризобиальными симбионтами. Так, в симбиотических клубеньках гороха (Pisum sativum L.) выявлено высокое содержание деэтерифицированного ГГ в первичных клеточных стенках в клетках зоны инфекции и в стенках инфекционных нитей клубеньков (14). Однако в более старых, неделящихся клетках метка JIM5 была в основном ограничена срединной пластинкой. При изучении недетерминированных клубеньков на корнях Vicia hirsuta (L.) Gray и P. sativum, индуцированных R. leguminosarum, было показано, что в стенках инфекционной нити присутствовали целлюлоза, ксилоглюкан и ГГ с разной степенью метилэтерификации (10). У детерминированных клубеньков P. vulgaris наблюдались очень узкие инфекционные нити с практически отсутствующим матриксом и более плотной фибриллярной стенкой, которая обильно метилась антителом JIM5, распознающим деэтерифицированный ГГ (10). В симбиотических клубеньках P. sativum и M. truncatula локализация высокометилэтерифицированного ГГ, распознаваемого антителом ЈIM7, характерна для изодиаметрически растущих клеток, которые заполняются развивающимися бактероидами (41).

Локализацию и распределение ГГ анализировали при изучении других компонентов бобово-ризобиального интерфейса. Иммуноцитохимическое исследование нодулина ENOD2 - богатого пролином белка клеточной стенки, в клубеньках P. sativum и Glycine max (L.) Merr. показало, что деэтерифицированный ГГ соединяет межклеточные пространства, в которых накапливается ENOD2 (42). Позитивно заряженные лизиновые и гистидиновые остатки ENOD2 могут облегчать его взаимодействие с отрицательно заряженными боковыми цепями пектинов клеточной стенки, что способствует гелеобразованию пектина на границе клеточной стенки и межклеточного пространства (42). Важную роль в формировании симбиотического интерфейса в клубеньках $M$. truncatula играют компоненты везикулярного транспорта, в частности VAMP721d и VAMP721e (43). В клубеньках $G$. max с частично выключенным геном GmVAMP721d были обнаружены большие кластеры бактерий, погруженные в матрикс из метилэтерифицированного и деэтерифицированного ГГ, окруженные мембраной. Кроме того, GmVAMP721d частично колокализовался с пектатлиазой (44). Поэтому биологическую роль VAMP721d можно объяснить его участием в доставке ферментов, модифицирующих пектин, к месту высвобождения ризобий в цитоплазму клетки-хозяина. Также в этих клубеньках наблюдался аномальный эндоцитоз деэтерифицированного ГГ в молодых инфицированных клетках (44).

Иммуноцитохимическое исследование дефицитных по бору растений $P$. sativum показало, что в отличие от контрольных клубеньков, деэтерифицированный ГГ, распознаваемый антителом JIM5, локализовался равномерно по всей толщине клеточной стенки и даже в цитоплазме (45, 46). При этом распределение высокометилэтерифицированного ГГ, распознаваемого антителом JIM7, не менялось. Для выяснения возможного участия пектинов в ингибировании роста, опосредованного алюминием, было исследовано распределение ГГ с различной степенью метилэтерификации в апопласте клубеньков P. sativum (47). При обработке алюминием количество метки эпитопов деэтерифицированного ГГ и ГГ с поперечными кальциевыми сшивками в толстых стенках инфекционных нитей увеличивалось. Напротив, эпитоп высокометилэтерифицированного ГГ равномерно распределялся по всем клеточным стенкам в клубеньках, а при обработке его количество снижалось. Эти результаты указывают на специфическую роль 
деэтерификации ГГ в процессе утолщения клеточной стенки и ингибирования роста (47).

При изучении неэффективного бобово-ризобиального взаимодействия с использованием симбиотических мутантов $P$. sativum было показано, что у одиночных и двойных мутантов, несущих мутацию в гене $P S S y m 33$, обильное отложение деэтерифицированного ГГ, меченного антителом JIM5, наблюдалось в стенках инфекционных нитей (11). У мутанта RisFixV (Pssym 42) деэтерифицированный ГГ неравномерно распределялся в пропитанных каллозой стенках инфекционных нитей и клеточных стенках инфицированных клеток. Другой особенностью RisFixV (Pssym42) было присутствие метки JIM5 вокруг деградирующих бактероидов, что указывает на инкапсуляцию деэтерифицированным ГГ неэффективных бактероидов (11). В мутантах гороха без аномалий в развитии инфекционных нитей - SGEFix -3 (Pssym26) и Sprint-2Fix- (Pssym31), распределение деэтерифицированного ГГ не отличалось от такового у дикого типа, и количество ГГ было незначительным (41).

В клубеньках неэффективных симбиотических мутантов M. truncatula ipd3, dnfl-1 и efd-1 наблюдалась схожая картина распределения деэтерифицированного ГГ (41). При этом у всех мутантных генотипов M. truncatula количество отложенного деэтерифицированного ГГ было ниже, чем у дикого типа. Однако с возрастом в клубеньках у мутанта ipd3 содержание деэтерифицированного ГГ возрастало. Интересно отметить, что удвоение количества метки для деэтерифицированного ГГ наблюдалось также у мутанта $M$. truncatula по гену dnfl-1, который характеризуется недифференцированными бактероидами (41).

Рамногалактуронан II клеточных стенок при формировании симбиотических клубеньков. РГ-ІІ составляет $10 \%$ пектина и является наиболее сложным, но также и наиболее структурно консервативным пектиновым полисахаридом. Известно, что молекулы РГ-ІІ самосопряжены, образуя димеры РГ-ІІ через диэфирную связь с бором $(17,18)$. Сложный и консервативный РГ-ІІ с 12 различными сахарами в составе и более чем 20 типами связей имеет критическую функцию в росте и развитии растений, при этом даже незначительные изменения структуры РГ-ІІ могут негативно влиять на рост растений (вплоть до появления карликовости) (28). Накапливается все больше доказательств того, что бор и кальций действуют синергически при формировании первичной пектиновой сети клеточных стенок и что изменения в свойствах этой сети влияют на рост растений (48-50). Пектины клеточных стенок, в частности РГ-ІІ, содержат более 60 \% от общего количества бора в клетке. Многочисленные исследования показали, что бор - необходимый микроэлемент при развитии бобово-ризобиального симбиоза $(48,50-54)$.

Имеющиеся в настоящее время антитела к РГ-ІІ детально не охарактеризованы, что ограничивает их использование для определения локализации РГ-ІІ в клеточной стенке (49). Однако результаты, полученные с использованием этих антител, позволяют предположить, что РГ-II распределяется по всей первичной стенке и особенно обилен вблизи плазматической мембраны (в отличие от срединной пластинки, где он отсутствует) (55). После щелочной обработки некоторых, но не всех тканей количество метки в первичных стенках увеличивается, то есть можно предположить, что эпитопы, распознаваемые антителами к РГ-ІІ, маскируются вследствие этерификации (49).

При изучении клубенькообразования у контрольных растений $P$. sativum выявили локализацию РГ-ІІ в интерфейсе между плазматической 
мембраной и клеточной стенкой (46). У дефицитных по бору растений в отличие от контрольных клубеньков метка РГ-ІІ располагалась равномерно по всей толщине клеточной стенки и даже в цитоплазме, при этом добавление $\mathrm{Ca}^{2+}$ не восстанавливало исходную локализацию PГ-II полностью (46). Позднее было показано, что в клубеньках контрольных растений P. sativum РГ-II также локализовался на перибактероидной мембране недифференцированных бактероидов, однако затем постепенно исчезал во время созревания бактероидов (45). В дефицитных по бору клубеньках симбиосомы дифференцировались аберрантно и РГ-ІІ отсутствовал на перибактероидной мембране вследствие аномального транспорта везикул, содержащих пектин, к клеточным мембранам (45). У контрольных растений P. sativum комплекс РГ-II с бором и арабиногалактанпротеин-экстензином наблюдали в матриксе инфекционных нитей, который был отделен от клеток ризобий экзополисахаридной капсулой (56). В клубеньках дефицитных по бору растений арабиногалактанпротеин-экстензиновый комплекс с РГ-ІІ был тесно связан с поверхностью ризобий в просвете инфекционных нитей (56). Кроме того, колонии ризобий в свободноживущей культуре, выращенные без добавления бора, слабо формировали капсулу.

У растений G. max с частично выключенным геном GmVAMP721d распределение РГ-ІІ не изменялось по сравнению с таковым у контрольных клубеньков (44).

Рамногалактуронан I клеточных стенок при формировании симбиотических клубеньков. РГ-І составляет 20-35\% всего пектина клеточных стенок. Основа РГ-I состоит из чередующихся $(1,2)-$ связанных остатков $\alpha$-L-рамнозы и $(1,4)$-связанных остатков $\alpha$-D-галактуроновой кислоты. В зависимости от типа клетки и стадии развития до 20 $80 \%$ остатков рамнозы связаны с боковыми (преимущественно линейными, но также и разветвленными) арабиновыми, галактановыми, арабиногалактановыми или фукозиловыми цепями $(17,18)$. РГ-I, при всех различиях его структуры, обычно входит в состав тонких первичных клеточных стенок, где играет роль своеобразного «клея» для сцепления с соседними клетками (57). При этом специфичный для ткани и стадии развития вариант РГ-І охарактеризован пока только для одного типа клеток - растительных волокон, формирующих так называемый желатинозный тип клеточных стенок $(57,58)$. РГ-I - наиболее структурно гетерогенный пектин, а распространенность и состав боковых цепей РГ-І значительно различается в зависимости от типа клеток, стадии развития и вида растения (39). Основная цепь РГ-І играет важную роль в целостности и функционировании клеточной стенки, поскольку ее деградация вследствие экспрессии гидролаз приводит к морфологическим изменениям (33). При этом часть молекул РГ-I взаимодействует с микрофибриллами целлюлозы, а РГ-I с галактановыми боковыми цепями со средней степенью полимеризации способен к самосвязыванию за счет галактозных цепей (57). Изучение РГI в связи с функциями клеток сосредоточены на роли этого полисахарида в обеспечении механических свойств клеточной стенки, таких как ее твердость и эластичность $(23,57,59)$. Однако основной вклад РГ-I, богатого галактаном, в механическую твердость клеточной стенки неизвестен.

Иммуноэлектронное микроскопическое исследование показало, что распространение РГ-I в тканях листьев и корней ограничивается срединной пластинкой, причем 80-90 \% метки связано с расширенными областями срединной пластинки в углах соединений между клетками. При росте клеток растяжением РГ-I присутствует в цистернах и везикулах аппарата Гольджи, чем подтверждается, что аппарат Гольджи служит основным 
местом синтеза нецеллюлозных полисахаридов клеточной стенки. Кроме того, было обнаружено, что РГ-І практически отсутствует в формирующейся клеточной пластинке при делении клеток $(60,61)$.

Функции боковых цепей РГ-І по-прежнему в основном неясны. Для арабиновых и галактановых боковых цепей РГ-I характерны четкие и часто взаимоисключающие закономерности локализации; в целом арабинан, как правило, преобладает в более молодых клетках, в то время как во время роста растяжением клеток обычно выше доля галактана $(19,21,23$, $62,63)$. Замена арабинанов галактанами в эпидермальных клетках указывает на переход к дифференцировке этих клеток и делает клеточные стенки менее гибкими и более устойчивыми к деградации. Предполагается, что комплементарный рисунок эпитопа галактановых боковых цепей РГ-I может отражать необходимость поддержания упругих свойств в ткани с высокой плотностью ситовидных элементов (64).

У Arabidopsis $(1,5)-\alpha-\mathrm{L}$ арабиновые боковые цепи РГ-I многочисленны в клеточной стенке пыльцевой трубки. Они могут играть важную роль в предотвращении образования связей ГГ-полимеров и участвуют в прикреплении клеток (65). Процессы полярного роста кончиков пыльцевых трубок и инфекционных нитей на ранних стадиях ризобиальной инфекции могут иметь сходные механизмы и регуляторы (34). Однако до недавнего времени роль РГ-І в развитии бобово-ризобиального симбиоза не изучалась. Нами было впервые исследовано распределение РГ-І в бобоворизобиальных клубеньках у $P$. sativum и $M$. truncatula $(41,66)$. Для этого использовали антитела LM5, распознающие $(1 \rightarrow 4)-\beta$-галактановую боковую цепь РГ-І. Флуоресцентную метку регистрировали в клеточных стенках клеток меристемы и проводящих пучков в клубеньках обоих видов, а также в эндодерме, клетки которой служат «кислородным барьером», и в местах соединения трех клеток в клубеньках гороха. Кроме того, антитело LM5 маркировало стенки инфекционных нитей в клубеньках $P$. sativum, но метка отсутствовала в клубеньках M. truncatula. В то же время у мутанта гороха SGEFix ${ }^{-} 2$ (Pssym33-3) в стенках некоторых инфекционных нитей метка антителами LM5 отсутствовала, а у мутанта SGEFix-3 (Pssym 26) происходило аномальное накопление эпитопа галактановой боковой цепи РГ-I в клеточной стенке неинфицированных клеток в зоне старения клубеньков (41).

Недавно обнаруженная способность бактерии Pectobacterium atrosepticum формировать бактериальные эмболы в сосудах первичной ксилемы (67) проливает свет на возможную роль РГ-І при развитии неэффективных клубеньков. Так, нами при изучении мутанта SGEFix-2 (Pssym33-3) P. sativum было обнаружено, что в клубеньках в инфицированных клетках вокруг тонопласта откладывался материал клеточной стенки, содержащий высокометилэтерифицированный ГГ и линейную $(1 \rightarrow 4)-\beta$-галактановую боковую цепь РГ-I (66). Кроме того, этот материал формировал выросты и каплеподобные включения в просвет вакуоли. В некоторых инфекционных нитях наблюдался электронно-плотный матрикс с меткой антитела LM5, в который были погружены ризобии. Эти фенотипические проявления мутации в гене PsSym33 напоминают формирование бактериальных эмбол при инвазии P. atrosepticum (67). Ранее у мутанта Pssym33-3 были описаны интенсивные защитные реакции - суберинизация, отложение деэтерифицированного ГГ в стенках инфекционных нитей и усиление экспрессии гена, кодирующего пероксидазу (11). Отложение материала клеточной стенки вокруг тонопласта и формирование пектинового геля в матриксе инфекционных нитей служат еще одним из проявлений защит- 
ной реакции растения-хозяина и восприятия ризобии как патогена.

Итак, один из основных компонентов клеточной стенки - пектин играет важную роль в становлении и функционировании симбиотического интерфейса в клубеньках бобовых растений. В настоящее время проанализирована роль всех трех основных типов пектинов: гомогалактуронана, рамногалактуронана-I и рамногалактуронана-II, однако полнота представлений о функции каждого типа пектина неравнозначна. Наиболее изучен гомогалактуронан, что объясняется наличием высокоспецифичных моноклональных антител к этому полисахариду. Функция гомогалактуронана в клубеньках определяется степенью его метилирования. Показано, что гомогалактуронан с низкой степенью метилирования участвует в повышении ригидности клеточных стенок и стенок инфекционных нитей, особенно при неэффективном взаимодействии с ризобиями и влиянии абиотических стрессов. Высокометилэтерефицированный гомогалактуронан присутствует на всех стадиях развития клубенька. Изучение рамногалактуронана-II осложняется отсутствием охарактеризованных антител. Однако сообщается, что в клубеньках рамногалактуронан-II присутствует в клеточных стенках на границе с плазматической мембраной, в недифференцированных симбиосомах, а также в матриксе инфекционных нитей. Предполагается, что рамногалактуронан-II, формируя комплекс с бором и арабиногалактанпротеин-экстензинами, облегчает продвижение ризобий в инфекционных нитях. В отношении рамногалактуронана-I, роль которого в развитии клубеньков оставалась до недавних пор неизученной, нами показано, что он присутствуют в клеточной стенке клеток меристемы, проводящих пучков и стенках инфекционных нитей. Однако точная функция рамногалактуронана-I все еще не ясна. Таким образом, в настоящее время известно об участии всех типов пектинов в развитии симбиотических клубеньков, но выявление их конкретных функций требует дальнейшего исследования. В частности, анализ рамногалактуронана-II в неэффективных клубеньках мутантов с нарушениями в развитии инфекционной нити может подтвердить гипотезу его участия в росте инфекционной нити и продвижении в ней бактерий. Изучение рамногалактуронана-I и его боковых цепей с использованием различных антител представляет большой интерес для подтверждения видоспецифичности состава стенок инфекционных нитей.

\section{ЛИТЕРАТУРА}

1. Cosgrove D.J. Growth of the plant cell wall. Nat. Rev. Mol. Cell Biol., 2005, 6(11): 850-861 (doi: 10.1038/nrm1746).

2. Malinovsky F.G., Fangel J.U., Willats W.G.T. The role of the cell wall in plant immunity. Front. Plant. Sci., 2014, 5: 178 (doi: 10.3389/fpls.2014.00178).

3. Keegstra K. Plant cell walls. Plant Physiol., 2010, 154(2): 483-486 (doi: 10.1104/pp.110.161240).

4. Lionetti V., Cervone F., Bellincampi D. Methyl esterification of pectin plays a role during plant-pathogen interactions and affects plant resistance to diseases. J. Plant Physiol., 2012, 169(16): 1623-1630 (doi: 10.1016/j.jplph.2012.05.006).

5. Palin R., Geitmann A. The role of pectin in plant morphogenesis. Biosystems, 2012, 109(3): 397-402 (doi: 10.1016/j.biosystems.2012.04.006).

6. Bellincampi D., Cervone F., Lionetti V. Plant cell wall dynamics and wall-related susceptibility in plant-pathogen interactions. Front. Plant. Sci., 2014, 5: 228 (doi: 10.3389/fpls.2014.00228).

7. Brewin N.J. Plant cell wall remodelling in the Rhizobium-legume symbiosis. Crit. Rev. Plant Sci., 2004, 23(4): 293-316 (doi: 10.1080/07352680490480734).

8. Rich M.K., Schorderet M., Reinhardt D. The role of the cell wall compartment in mutualistic symbioses of plants. Front. Plant. Sci., 2014, 5: 238 (doi: 10.3389/fpls.2014.00238).

9. Parniske M. Intracellular accommodation of microbes by plants: a common developmental program for symbiosis and disease? Curr. Opin. Plant Biol., 2000, 3(4): 320-328 (doi: 10.1016/S1369-5266(00)00088-1). 
10. Rae A.L., Bonfante-Fasolo P., Brewin N.J. Structure and growth of infection threads in the legume symbiosis with Rhizobium leguminosarum. Plant J., 1992, 2(3): 385-395 (doi: 10.1111/j.1365313X.1992.00385.x).

11. Ivanova K.A., Tsyganova A.V., Brewin N.J., Tikhonovich I.A., Tsyganov V.E. Induction of host defences by Rhizobium during ineffective nodulation of pea (Pisum sativum L.) carrying symbiotically defective mutations sym40 (PsEFD), sym33 (PsIPD3/PsCYCLOPS) and sym 42. Protoplasma, 2015, 252(6): 1505-1517 (doi: 10.1007/s00709-015-0780-y).

12. Цыганова А.В., Цыганов В.Е., Борисов А.Ю., Тихонович И.А., Бревин Н.Д. Сравнительный цитохимический анализ распределения перекиси водорода у неэффективного мутанта гороха SGEFix-1 (sym40) и исходной линии SGE. Экологическая генетика, 2009, 7(3): 3-9.

13. Bradley D.J., Wood E.A., Larkins A.P., Galfre G., Butcher G.W., Brewin N.J. Isolation of monoclonal antibodies reacting with peribacteriod membranes and other components of pea root nodules containing Rhizobium leguminosarum. Planta, 1988, 173(2): 149-160 (doi: 10.1007/bf00403006).

14. VandenBosch K.A., Bradley D.J., Knox J.P., Perotto S., Butcher G.W., Brewin N.J. Common components of the infection thread matrix and the intercellular space identified by immunocytochemical analysis of pea nodules and uninfected roots. EMBO J., 1989, 8(2): 335 341 (doi: 10.1002/j.1460-2075.1989.tb03382.x).

15. Vincken J.-P., Schols H.A., Oomen R.J., McCann M.C., Ulvskov P., Voragen A.G., Visser R.G. If homogalacturonan were a side chain of rhamnogalacturonan I. Implications for cell wall architecture. Plant Physiol., 2003, 132(4): 1781-1789 (doi: 10.1104/pp.103.022350).

16. Anderson C.T. We be jammin': an update on pectin biosynthesis, trafficking and dynamics. J. Exp. Bot., 2015, 67(2): 495-502 (doi: 10.1093/jxb/erv501).

17. Atmodjo M.A., Hao Z., Mohnen D. Evolving views of pectin biosynthesis. Annu. Rev. Plant Biol., 2013, 64(1): 747-779 (doi: 10.1146/annurev-arplant-042811-105534).

18. Caffall K.H., Mohnen D. The structure, function, and biosynthesis of plant cell wall pectic polysaccharides. Carbohydr. Res., 2009, 344(14): 1879-1900 (doi: 10.1016/j.carres.2009.05.021).

19. Saffer A.M. Expanding roles for pectins in plant development. J. Integr. Plant. Biol., 2018, 60(10): 910-923 (doi: 10.1111/jipb.12662).

20. Larskaya I.A., Gorshkova T.A. Plant oligosaccharides — outsiders among elicitors? Biochemistry (Moscow), 2015, 80(7): 881-900 (doi: 10.1134/s0006297915070081).

21. Willats W.G., Steele-King C.G., Marcus S.E., Knox J.P. Side chains of pectic polysaccharides are regulated in relation to cell proliferation and cell differentiation. Plant J., 1999, 20(6): 619628 (doi: 10.1046/j.1365-313X.1999.00629.x ).

22. Peaucelle A., Louvet R., Johansen J.N., Höfte H., Laufs P., Pelloux J., Mouille G. Arabidopsis phyllotaxis is controlled by the methyl-esterification status of cell-wall pectins. Curr. Biol., 2008, 18(24): 1943-1948 (doi: 10.1016/j.cub.2008.10.065).

23. McCartney L., Ormerod A.P., Gidley M.J., Knox J.P. Temporal and spatial regulation of pectic $(1 \rightarrow 4)-\beta$-D-galactan in cell walls of developing pea cotyledons: implications for mechanical properties. Plant J., 2000, 22(2): 105-113 (doi: 10.1046/j.1365-313x.2000.00719.x).

24. Mohnen D. Pectin structure and biosynthesis. Curr. Opin. Plant Biol., 2008, 11(3): 266-277 (doi: 10.1016/j.pbi.2008.03.006).

25. Wolf S., Mouille G., Pelloux J. Homogalacturonan methyl-esterification and plant development. Mol. Plant, 2009, 2(5): 851-860 (doi: 10.1093/mp/ssp066).

26. Lievens S., Goormachtig S., Herman S., Holsters M. Patterns of pectin methylesterase transcripts in developing stem nodules of Sesbania rostrata. Mol. Plant-Microbe Interact., 2002, 15(2): 164-168 (doi: 10.1094/MPMI.2002.15.2.164).

27. Prade R.A., Zhan D., Ayoubi P., Mort A.J. Pectins, pectinases and plant-microbe interactions. Biotechnol. Genet. Eng. Rev., 1999, 16(1): 361-392 (doi: 10.1080/02648725.1999.10647984).

28. Levesque-Tremblay G., Pelloux J., Braybrook S.A., Müller K. Tuning of pectin methylesterification: consequences for cell wall biomechanics and development. Planta, 2015, 242(4): 791-811 (doi: 10.1007/s00425-015-2358-5).

29. Wolf S., Greiner S. Growth control by cell wall pectins. Protoplasma, 2012, 249(2): 169-175 (doi: 10.1007/s00709-011-0371-5).

30. Pelloux J., Rustérucci C., Mellerowicz E.J. New insights into pectin methylesterase structure and function. Trends Plant Sci., 2007, 12(6): 267-277 (doi: 10.1016/j.tplants.2007.04.001).

31. Lionetti V., Fabri E., De Caroli M., Hansen A.R., Willats W.G.T., Piro G., Bellincampi D. Three pectin methylesterase inhibitors protect cell wall integrity for Arabidopsis immunity to Botrytis. Plant Physiol., 2017, 173(3): 1844-1863 (doi: 10.1104/pp.16.01185).

32. Peaucelle A., Braybrook S.A., Le Guillou L., Bron E., Kuhlemeier C., Höfte H. Pectin-induced changes in cell wall mechanics underlie organ initiation in Arabidopsis. Curr. Biol., 2011, 21(20): 1720-1726 (doi: 10.1016/j.cub.2011.08.057).

33. Pogorelko G., Lionetti V., Bellincampi D., Zabotina O. Cell wall integrity: Targeted post- 
synthetic modifications to reveal its role in plant growth and defense against pathogens. Plant Signal Behav., 2013, 8(9): e25435 (doi: 10.4161/psb.25435).

34. Rodríguez-Llorente I.D., Pérez-Hormaeche J., Mounadi K.E., Dary M., Caviedes M.A., Cosson V., Kondorosi A., Ratet P., Palomares A.J. From pollen tubes to infection threads: recruitment of Medicago floral pectic genes for symbiosis. Plant J., 2004, 39(4): 587-598 (doi: 10.1111/j.1365-313X.2004.02155.x).

35. Fauvart M., Verstraeten N., Dombrecht B., Venmans R., Beullens S., Heusdens C., Michiels J. Rhizobium etli $\mathrm{HrpW}$ is a pectin-degrading enzyme and differs from phytopathogenic homologues in enzymically crucial tryptophan and glycine residues. Microbiology, 2009, 155(9): 3045-3054 (doi: 10.1099/mic.0.027599-0).

36. Mucoz J.A., Coronado C., Pérez-Hormaeche J., Kondorosi A., Ratet P., Palomares A.J. MsPG3, a Medicago sativa polygalacturonase gene expressed during the alfalfa-Rhizobium meliloti interaction. PNAS USA, 1998, 95(16): 9687-9692 (doi: 10.1073/pnas.95.16.9687).

37. Xie F., Murray J.D., Kim J., Heckmann A.B., Edwards A., Oldroyd G.E.D., Downie J.A. Legume pectate lyase required for root infection by rhizobia. PNAS USA, 2012, 109(2): 633-638 (doi: 10.1073/pnas.1113992109).

38. Knox J.P., Linstead P.J., King J., Cooper C., Roberts K. Pectin esterification is spatially regulated both within cell walls and between developing tissues of root apices. Planta, 1990, 181(4): 512-521 (doi: 10.1007/bf00193004).

39. Verhertbruggen Y., Marcus S.E., Haeger A., Ordaz-Ortiz J.J., Knox J.P. An extended set of monoclonal antibodies to pectic homogalacturonan. Carbohydr. Res., 2009, 344(14): 1858-1862 (doi: 10.1016/j.carres.2008.11.010).

40. Guillemin F., Guillon F., Bonnin E., Devaux M.-F., Chevalier T., Knox J.P., Liners F., Thibault J.-F. Distribution of pectic epitopes in cell walls of the sugar beet root. Planta, 2005, 222(2): 355-371 (doi: 10.1007/s00425-005-1535-3).

41. Tsyganova A.V., Seliverstova E.V., Ivanova K.A., Brewin N.J., Tsyganov V.E. Comparative analysis of remodelling of the plant-microbe interface in Pisum sativum and Medicago truncatula symbiotic nodules. Protoplasma, 2019, 256(4): 983-996 (doi: 10.1007/s00709-019-01355-5).

42. Sherrier D.J., Taylor G.S., Silverstein K.A.T., Gonzales M.B., VandenBosch K.A. Accumulation of extracellular proteins bearing unique proline-rich motifs in intercellular spaces of the legume nodule parenchyma. Protoplasma, 2005, 225(1): 43-55 (doi: 10.1007/s00709-005-0090-x).

43. Ivanov S., Fedorova E.E., Limpens E., De Mita S., Genre A., Bonfante P., Bisseling T. Rhizobium-legume symbiosis shares an exocytotic pathway required for arbuscule formation. PNAS USA, 2012, 109(21): 8316-8321 (doi: 10.1073/pnas.1200407109).

44. Gavrin A., Chiasson D., Ovchinnikova E., Kaiser B.N., Bisseling T., Fedorova E.E. VAMP721a and VAMP721d are important for pectin dynamics and release of bacteria in soybean nodules. New Phytol., 2016, 210(3): 1011-1021 (doi: 10.1111/nph.13837).

45. Redondo-Nieto M., Pulido L., Reguera M., Bonilla I., Bolaños L. Developmentally regulated membrane glycoproteins sharing antigenicity with rhamnogalacturonan II are not detected in nodulated boron deficient Pisum sativum. Plant Cell Environ., 2007, 30(11): 1436-1443 (doi: 10.1111/j.1365-3040.2007.01721.x).

46. Redondo-Nieto M., Wilmot A.R., El-Hamdaoui A., Bonilla I., Bolaños L. Relationship between boron and calcium in the $\mathrm{N}_{2}$-fixing legume-rhizobia symbiosis. Plant Cell Environ., 2003, 26(11): 1905-1915 (doi: 10.1046/j.1365-3040.2003.01107.x).

47. Sujkowska-Rybkowska M., Borucki W. Pectins esterification in the apoplast of aluminumtreated pea root nodules. J. Plant Physiol., 2015, 184: 1-7 (doi: 10.1016/j.jplph.2015.05.011).

48. Carpena R.O., Esteban E., Sarro M.J., Pecalosa J., Gárate A.N., Lucena J.J., Zornoza P. Boron and calcium distribution in nitrogen-fixing pea plants. Plant Sci., 2000, 151(2): 163-170 (doi: 10.1016/S0168-9452(99)00210-1).

49. O’Neill M.A., Ishii T., Albersheim P., Darvill A.G. Rhamnogalacturonan II: structure and function of a borate cross-linked cell wall pectic polysaccharide. Annu. Rev. Plant Biol., 2004, 55(1): 109-139 (doi: 10.1146/annurev.arplant.55.031903.141750).

50. Redondo-Nieto M., Maunoury N., Mergaert P., Kondorosi E., Bonilla I., Bolaños L. Boron and calcium induce major changes in gene expression during legume nodule organogenesis. Does boron have a role in signalling? New Phytol., 2012, 195(1): 14-19 (doi: 10.1111/j.14698137.2012.04176.x).

51. Bolaños L., Brewin N.J., Bonilla I. Effects of Boron on Rhizobium-legume cell-surface interactions and nodule development. Plant Physiol., 1996, 110(4): 1249-1256 (doi: 10.1104/pp.110.4.1249).

52. Bolaños L., Cebrián A., Redondo-Nieto M., Rivilla R., Bonilla I. Lectin-like glycoprotein PsNLEC-1 is not correctly glycosylated and targeted in boron-deficient pea nodules. Mol. Plant-Microbe Interact., 2001, 14(5): 663-670 (doi: 10.1094/MPMI.2001.14.5.663).

53. Bolaños L., Esteban E., de Lorenzo C., Fernandez-Pascual M., de Felipe M.R., Garate A., Bonilla I. Essentiality of boron for symbiotic dinitrogen fixation in pea (Pisum sativum) rhizobium nodules. Plant Physiol., 1994, 104(1): 85-90 (doi: 10.1104/pp.104.1.85). 
54. Bonilla I., Mergold-Villasenor C., Campos M.E., Sanchez N., Perez H., Lopez L., Castrejon L., Sanchez F., Cassab G.I. The aberrant cell walls of boron-deficient bean root nodules have no covalently bound hydroxyproline/proline-rich proteins. Plant Physiol., 1997, 115(4): 1329-1340 (doi: 10.1104/pp.115.4.1329).

55. Matoh T., Takasaki M., Takabe K., Kobayashi M. Immunocytochemistry of rhamnogalacturonan II in cell walls of higher plants. Plant Cell Physiol., 1998, 39(5): 483-491 (doi: 10.1093/oxfordjournals.pcp.a029395).

56. Reguera M., Abreu I., Brewin N.J., Bonilla I., Bolaños L. Borate promotes the formation of a complex between legume AGP-extensin and rhamnogalacturonan II and enhances production of Rhizobium capsular polysaccharide during infection thread development in Pisum sativum symbiotic root nodules. Plant Cell Environ., 2010, 33(12): 2112-2120 (doi: 10.1111/j.13653040.2010.02209.x).

57. Горшкова Т.А., Козлова Л.В., Микшина П.В. Пространственная структура полисахаридов растительных клеточных стенок и ее функциональная значимость (обзор). Биохимия, 2013, 78(7): 1068-1088.

58. Микшина П.В., Петрова А.А., Файзуллин Д.А., Зуев Ю.Ф., Горшкова Т.А. Рамногалактуронан I желатинозных волокон льна формирует гель, обладающий гиперэластичными свойствами. Биохимия, 2015, 80(7): 1088-1098.

59. Lee K.J.D., Cornuault V., Manfield I.W., Ralet M.-C., Knox P.J. Multi-scale spatial heterogeneity of pectic rhamnogalacturonan I (RG-I) structural features in tobacco seed endosperm cell walls. Plant J., 2013, 75(6): 1018-1027 (doi: 10.1111/tpj.12263).

60. Jones L., Seymour G.B., Knox J.P. Localization of pectic galactan in tomato cell walls using a monoclonal antibody specific to $(1 \rightarrow 4)-\beta-D$-galactan. Plant Physiol., 1997, 113(4): 1405-1412 (doi: 10.1104/pp.113.4.1405).

61. Moore P.J., Staehelin L.A. Immunogold localization of the cell-wall-matrix polysaccharides rhamnogalacturonan I and xyloglucan during cell expansion and cytokinesis in Trifolium pratense L.; implication for secretory pathways. Planta, 1988, 174(4): 433-445 (doi: 10.1007/bf00634471).

62. Corral-Martínez P., García-Fortea E., Bernard S., Driouich A., Seguí-Simarro J.M. Ultrastructural immunolocalization of arabinogalactan protein, pectin and hemicellulose epitopes through anther development in Brassica napus. Plant Cell Physiol., 2016, 57(10): 2161-2174 (doi: $10.1093 / \mathrm{pcp} / \mathrm{pcw} 133$ ).

63. Liu J., Hou J., Chen H., Pei K., Li Y., He X.-Q. Dynamic changes of pectin epitopes in cell walls during the development of the procambium-cambium continuum in poplar. Int. J. Mol. Sci., 2017, 18(8): 1716 (doi: 10.3390/ijms18081716).

64. Torode T.A., O'Neill R., Marcus S.E., Cornuault V., Pose S., Lauder R.P., Kračun S.K., Rydahl M.G., Andersen M.C., Willats W.G. Branched pectic galactan in phloem-sieve-element cell walls: implications for cell mechanics. Plant Physiol., 2018, 176(2): 1547-1558 (doi: 10.1104/pp.17.01568).

65. Lehner A., Dardelle F., Soret-Morvan O., Lerouge P., Driouich A., Mollet J.-C. Pectins in the cell wall of Arabidopsis thaliana pollen tube and pistil. Plant Signal Behav., 2010, 5(10): 12821285 (doi: 10.4161/psb.5.10.13040).

66. Tsyganova A.V., Seliverstova E.V., Brewin N.J., Tsyganov V.E. Bacterial release is accompanied by ectopic accumulation of cell wall material around the vacuole in nodules of Pisum sativum sym33-3 allele encoding transcription factor PsCYCLOPS/PsIPD3. Protoplasma, 2019 (doi: 10.1007/s00709-019-01383-1) [Epub ahead of print].

67. Gorshkov V.Y., Daminova A.G., Mikshina P.V., Petrova O.E., Ageeva M.V., Salnikov V.V., Gorshkova T.A., Gogolev Y.V. Pathogen-induced conditioning of the primary xylem vessels a prerequisite for the formation of bacterial emboli by Pectobacterium atrosepticum. Plant Biol., 2016, 18(4): 609-617 (doi: 10.1111/plb.12448).

ФГБНУ Всероссийский НИИ сельскохозяйственной микробиологии,

196608 Россия, г. Санкт-Петербург-Пушкин, ш. Подбельского, 3,

Поступила в редакцию

e-mail: isaakij@mail.ru, tsyganov@arriam.spb.ru凶

Sel'skokhozyaistvennaya biologiya [Agricultural Biology], 2019, V. 54, № 3, pp. 446-457

\section{PLANT CELL WALL IN SYMBIOTIC INTERACTIONS. PECTINS} (review)

\section{A.V. Tsyganova, V.E. Tsyganov}

All-Russian Research Institute for Agricultural Microbiology, 3, sh. Podbel'skogo, St. Petersburg, 196608 Russia, e-mail isaakij@mail.ru, tsyganov@arriam.spb.ru (凹 corresponding author) 
ORCID:

Tsyganova A.V. orcid.org/0000-0003-3505-4298

The authors declare no conflict of interests

Acknowledgements:

Supported financially by Russian Science Foundation (project № 16-16-10035)

Received January 22, 2019

doi: 10.15389/agrobiology.2019.3.446eng

\section{Abstract}

Since plant cells, unlike animals, are immobile and limited by rigid cell walls, often the properties of the plant extracellular matrix play a crucial role in the plant development. The extracellular matrix, in particular the cell walls, are involved in the molecular dialogue between partners during the interaction of plants and microorganisms during the formation of legume-rhizobial symbiosis (N.J. Brewin, 2004; M.K. Rich et al., 2014). Legume-rhizobial symbiosis is a convenient model for studying changes in the composition of the plant cell wall caused by interactions with bacteria. Colonization of host cells with nodule bacteria, rhizobia, involves the sequential reorganization of the plant-microbial interface. The bacterial components of the symbiotic interface include various surface polysaccharides (A.V. Tsyganova et al., 2012). Plant components include the cell wall, the extracellular matrix and the plasma membrane. In this review, we have summarized the data demonstrating the involvement of pectins, the polysaccharides of the cell wall matrix, in the legumerhizobial symbiosis (K.H. Caffall et al., 2009; M.A. Atmodjo et al., 2013; C.T. Anderson, 2015). The greatest progress has been made in the study of homogalacturonan, for which highly specific monoclonal antibodies have been obtained (J.P. Knox et al., 1990; Y. Verhertbruggen et al., 2009). The level of methyl-esterification of homogalacturonan determines its function in nodules. It was shown that low methyl-esterified homogalacturonan is involved in increasing the rigidity of the cell walls and walls of infection threads (K.A. VandenBosch et al., 1989; A.L. Rae et al., 1992) that is especially manifested in ineffective interaction with rhizobia (K.A. Ivanova et al., 2015) and during the action of abiotic factors (M. Redondo-Nieto et al., 2003, 2007; M. Sujkowska-Rybkowska et al., 2015). High methyl-esterified homogalacturonan is observed in the cell walls at all stages of nodule development (A.L. Rae et al., 1992; A.V. Tsyganova et al., 2019). The absence of well characterized antibodies complicates the study of rhamnogalacturonan-II (M.A. O'Neill et al., 2004). However, it was shown that in nodules rhamnogalacturonan-II is present in the cell wall at the border with the plasma membrane, in undifferentiated symbiosomes, and also in the matrix of infection threads (M. Redondo-Nieto et al., 2003, 2007; M. Reguera et al., 2010). Probably, rhamnogalacturonan-II in combination with boron and arabinogalactan-protein extensins promotes movement of rhizobia in the matrix of infectious threads (M. Reguera et al., 2010). Only recently, we conducted the first studies aimed at identifying the role of rhamnogalacturonan-I in the development of nodules (A.V. Tsyganova et al., 2019). It has been shown that rhamnogalacturonan-I is present in the cell wall of the meristem cells, vascular bundles and in the walls of the infectious threads. However, its precise function remains unknown, although it was suggested that rhamnogalacturonan-I is involved in the perception of rhizobia as pathogens during ineffective symbiosis (A.V. Tsyganova et al., 2019). Thus, to date, it has been shown that all types of pectins are involved in the development of a symbiotic nodule. It is important to note that plant plays a central role in the remodelling of the cell wall during symbiotic interaction and the construction of the plant-microbe interface.

Keywords: legume-rhizobial symbiosis, plant-microbe interface, cell wall, infection thread, homogalacturonan, rhamnogalacturonans.

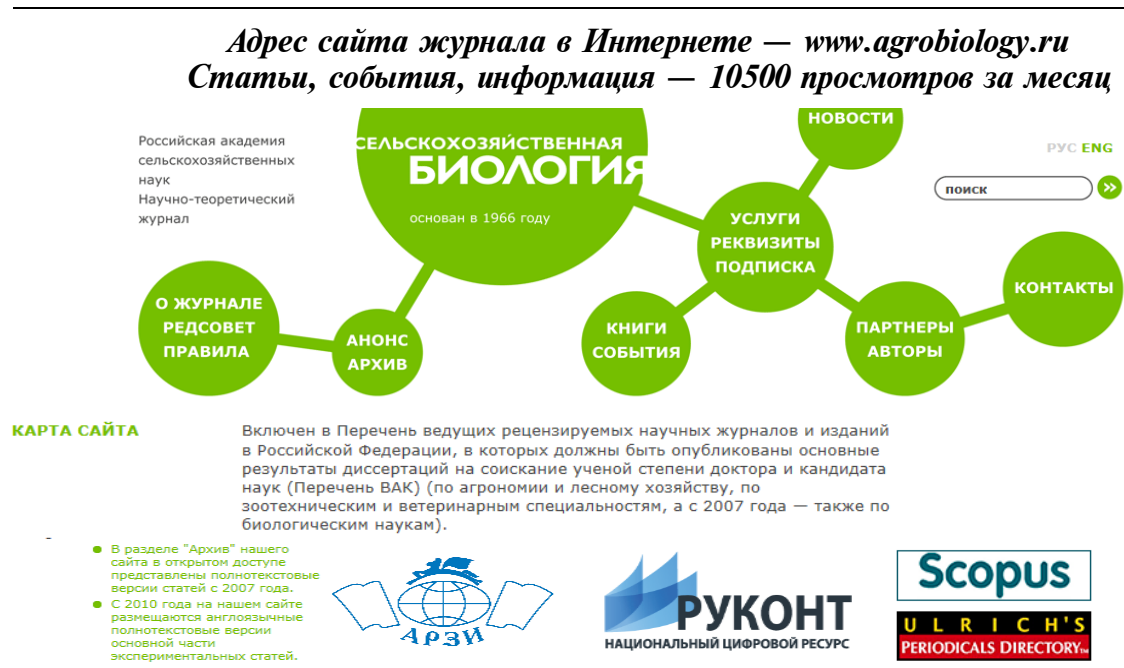

